\title{
Correlations Between a Dedicated Orthopaedic Complications Grading System and Early Adverse Outcomes in Joint Arthroplasty
}

\author{
Dorothy Y. Harris MD, Jillian K. McAngus MS, \\ Yong-Fang Kuo PhD, Ronald W. Lindsey MD
}

Received: 20 June 2014 / Accepted: 10 November 2014/Published online: 21 November 2014

(C) The Association of Bone and Joint Surgeons (R 2014

\begin{abstract}
Background Reliable classification of postoperative complications is important for quality improvement efforts. In 2014, The Knee Society proposed a grading system for complications after TKA, but to our knowledge, a relationship between complication grades and surgical outcomes has not yet been established.

Questions/purposes We attempted to determine (1) whether an association exists between complication grade and early adverse outcomes after TKA and THA, and (2) what proportion of the variability in complications could be associated with the classification grade (a metric of potential predictive value of the grading schema).

Methods A total of 210 primary THAs and TKAs in 201 patients performed at one center from January 1, 2011 to December 31, 2011 were reviewed; of those, 188 patients (94\%; 197 procedures) had complete 90-day postoperative data and were evaluated retrospectively for postoperative complications. We defined and graded complications according to the classification system proposed by Iorio
\end{abstract}

Each author certifies that he/she has no commercial associations (eg, consultancies, stock ownership, equity interest, patent/licensing arrangements, etc) that might pose a conflict of interest in connection with the submitted article.

All ICMJE Conflict of Interest Forms for authors and Clinical Orthopaedics and Related Research ${ }^{\mathbb{R}}$ editors and board members are on file with the publication and can be viewed on request. Each author certifies that his or her institution approved for the reporting of this investigation and that all investigations were conducted in conformity with ethical principles of research.

D. Y. Harris ( $₫)$, J. K. McAngus, Y.-F. Kuo, R. W. Lindsey Department of Orthopaedic Surgery and Rehabilitation,

University of Texas Medical Branch, 301 University Blvd,

Galveston, TX 77555-0165, USA

e-mail: dorothyharrismd@gmail.com et al. and The Knee Society. Early adverse outcomes assessed included length of hospital stay and unplanned readmissions or reoperations. A total of 254 complications were documented in 135 patients (137 procedures); 53 patients ( 60 procedures) had no complications. Bivariate analyses were conducted to identify associations between complication grade and early adverse outcomes and patient variables; analyses considered patient variables including age, sex, status as a state prisoner (yes or no), American Society of Anesthesiologists score, BMI, and procedure (TKA or THA). Multiple regression and logistic regression analyses were conducted to determine the association between complication grade and early adverse outcomes (length of stay [LOS] and unplanned readmission or reoperations) adjusted for confounding patient variables. Alpha was set at 0.05 for two-sided tests.

Results Maximum complication grade (range, from 0-4) was associated with a longer LOS (for each point increase of maximum grade, LOS increased $0.105 \pm 0.024$ days, $\mathrm{p}<0.001$ ) and more readmissions or reoperations (odds ratio $[\mathrm{OR}], 3.79 ; 95 \% \mathrm{CI}, 1.91-7.54 ; \mathrm{p}<0.001)$. Total grade (range, 0-22) also was associated with increased LOS (for each point increase of total grade, LOS increased $0.032 \pm 0.006$ days, $\mathrm{p}<0.001)$ and increased readmissions or reoperations (OR, 1.34; 95\% CI, 1.18-1.53; $\mathrm{p}<0.001$ ). Total grade could account for $38 \%$ of the variation in LOS and readmissions or reoperations (C-statistic $=0.94 ; 95 \%$ CI, 0.90-0.98); whereas maximum complication grade could account for $35 \%$ of the variation in LOS and readmissions or reoperations (C-statistic $=0.35 ; 95 \%$ CI, 0.88-0.96). Thus, we found total grade to be a slightly better predictor of LOS and readmissions or reoperations than maximum grade.

Conclusions We found that the proposed grading system is applicable to TKA and THA in terms of documentation 
of complication severity and as an indicator of increased LOS and increased unplanned readmissions or reoperation rates. That total complication grade was a better predictor of LOS than maximum grade suggests that multiple complications of a lesser grade can be just as important as a single higher grade complication in terms of effect on outcomes.

\section{Introduction}

Quality assessment has become an integral part of modern healthcare. For example, introduction of large databases such as the National Surgical Quality Improvement Program (ACS NSQIP ${ }^{\circledR}$ ) has provided an accurate, standardized, and reproducible method for recording surgical outcomes, essential for healthcare professionals, quality care entities, and others $[8,11]$. Postoperative complications usually are reported in the surgical literature and constitute the most frequently used surrogate marker of quality in surgery $[1,4,5,8-10]$. However, as reported by Sink et al. [23], there is "no universal definition, grading system, or classification for the magnitude of orthopaedic complications."

Because total joint arthroplasty is a highly used and costly procedure with substantial potential for complications, it is a focus of attention for policy makers, insurers, and providers. In 2014, The Knee Society created a complication classification scheme, based on the ClavienDindo Surgical Complication Classification System [13]. The Clavien-Dindo classification system initially was developed and validated for general surgery procedures [39, 14-22, 24, 25]. Although The Knee Society endorsed this modified classification system for improved standardization of reporting complications after knee replacement, they did not establish a relationship between the system's complication grades and surgical functional or economic outcomes.

We therefore sought to determine (1) whether an association exists between complication grade and early adverse outcomes after TKA and THA, and (2) what proportion of the variability in complications could be associated with the classification grade (a metric of the potential predictive value of the grading schema).

\section{Patients and Methods}

A total of 210 primary THAs and TKAs performed in 201 patients were reviewed at one center for January 1, 2011 to December 31, 2011; of those, complete 90-day postoperative data were available for 188 patients (197 procedures;
94\%) and were evaluated retrospectively. Exclusion criteria included revision arthroplasty and less than 90 days of patient-care followup data. Thirteen patients (13 procedures) were excluded owing to incomplete 90-day postoperative followup data. Thus, 188 patients with 197 primary total joint arthroplasties (108 knees and 89 hips) were reviewed for postoperative complications. Nine patients underwent bilateral arthroplasties during the collection period (five TKAs, four THAs).

Patient-care data collected included patient demographics - age and BMI at the time of surgery, sex, date of admission, date of discharge, type of procedure, status as a state prisoner (yes or no); and the American Society of Anesthesiologists (ASA) Physical Status classification.

Complications were determined by medical records review. We defined and identified complications according to the method of The Knee Society [12], which, by review of literature and expert consensus, developed a list of complications germane to TKAs which they recommended be included in complication reporting. Complications were graded according to the method of Iorio et al. [13] which stratifies complications according to treatment rendered (Table 1). We used The Knee Society complication list and the grading system of Iorio et al. without further modification to patients who underwent either TKA or THA. Complications were documented and graded for each patient by one author (DYH). None of the included patients could have simultaneous TKA and THA performed during the same hospital admission. If a patient underwent bilateral TKAs or THAs within 90 days of the index procedure, each procedure was documented as a separate procedure.

Primary outcomes evaluated for our study were length of stay (LOS) and unplanned readmissions or reoperations within 90 days of surgery. Bivariate analyses were conducted to identify associations between complication grade and early adverse outcomes (LOS and readmission or reoperation rates) and patient variables (sex, age, BMI, ASA score, status as a state prisoner). Chi-square test and ANOVA were used for categorical and continuous variables, respectively.

To quantify the magnitude of complication grade in patients with multiple complications, we introduced the concepts of total complication grade and maximum complication grade. Total complication grade is defined as the total combined sum of all complications. Maximum complication grade is defined as the highest graded complication noted. Multiple regression and logistic regression analyses subsequently were conducted to determine the association between total and maximum complication grades and LOS and 90-day readmissions or reoperations after adjusting for sex, age, BMI, ASA score, status as a state prisoner, and TKA or THA. Patient age and 
Table 1. Modification of adaptation by Sink et al. of Clavien-Dindo surgical complication classification system

\begin{tabular}{|c|c|c|}
\hline Grade & $\begin{array}{l}\text { Original definition per Sink } \\
\text { et al. [23] }\end{array}$ & $\begin{array}{l}\text { Modified definition for } \\
\text { arthroplasty complications }\end{array}$ \\
\hline I & $\begin{array}{l}\text { A complication that requires } \\
\text { no treatment and has no } \\
\text { clinical relevance; there is } \\
\text { no deviation from routine } \\
\text { followup during the } \\
\text { postoperative period; } \\
\text { allowed therapeutic } \\
\text { regimens include: } \\
\text { antiemetics, antipyretics, } \\
\text { analgesics, diuretics, } \\
\text { electrolytes, antibiotics, } \\
\text { and physiotherapy }\end{array}$ & No change \\
\hline II & $\begin{array}{l}\text { A deviation from the normal } \\
\text { postoperative course } \\
\text { (including unplanned clinic } \\
\text { visits) that requires } \\
\text { outpatient treatment: either } \\
\text { pharmacologic or close } \\
\text { monitoring as an outpatient }\end{array}$ & No change \\
\hline III & $\begin{array}{l}\text { A complication that is } \\
\text { treatable but requires } \\
\text { surgical, endoscopic, or } \\
\text { radiographic interventions } \\
\text { or an unplanned hospital } \\
\text { admission }\end{array}$ & $\begin{array}{l}\text { A complication that is } \\
\text { treatable[ but requires } \\
\text { surgical, arthroscopic, or } \\
\text { radiographic interventions, } \\
\text { closed manipulation of the } \\
\text { knee with the patient under } \\
\text { anesthesia, or an unplanned } \\
\text { hospital admission or } \\
\text { prolonged index } \\
\text { admission* }\end{array}$ \\
\hline IV & $\begin{array}{l}\text { A complication that is life- } \\
\text { threatening, requires ICU } \\
\text { admission, or is not } \\
\text { treatable, with potential for } \\
\text { permanent disability; a } \\
\text { complication that requires } \\
\text { organ resection (THA) }\end{array}$ & $\begin{array}{l}\text { A complication that is life- } \\
\text { threatening, requires ICU } \\
\text { admission, or is not } \\
\text { treatable, with potential for } \\
\text { permanent disability; a } \\
\text { complication that requires } \\
\text { resection, arthroplasty, } \\
\text { arthrodesis, or amputation }\end{array}$ \\
\hline V & Death & No change \\
\hline
\end{tabular}

* Prolonged index admission was not used as criteria for assessing grade as no predetermined length of stay for primary arthroplasty has been established and accepted at our institution; ICU = intensive care unit; (Adapted from Sink EL, Beaulé PE, Sucato D, Kim YJ, Millis MB, Dayton M, Trousdale RT, Sierra RJ, Zaltz I, Schoenecker P, Monreal A, Clohisy J. Multicenter study of complications following surgical dislocation of the hip. J Bone Joint Surg Am. 2011;93:11321136.)

BMI were categorized in the analyses. All tests were twosided with an alpha of 0.05 .

A total of 254 complications in 135 patients who underwent 137 TKAs and THAs were documented. The remaining 60 procedures $(30.5 \%)$ in 53 patients were associated with no postoperative complications.

Mean patient age was $58.5 \pm 13.5$ years (range, 2294 years). The study cohort consisted of 108 men (55\%)
Table 2. Patient demographics, complications grade, readmission and reoperation rates, and LOS

\begin{tabular}{|c|c|c|c|c|c|c|}
\hline \multirow[t]{2}{*}{ Parameter } & \multicolumn{2}{|c|}{ Total $(\mathrm{n}=197)$} & \multicolumn{2}{|c|}{ Knee $(\mathrm{n}=108)$} & \multicolumn{2}{|c|}{ Hip $(n=89)$} \\
\hline & Number & $\%$ & Number & $\%$ & Number & $\%$ \\
\hline \multicolumn{7}{|l|}{ Age (years) } \\
\hline$<65$ & 131 & 67 & 67 & 62 & 64 & 72 \\
\hline$\geq 65$ & 66 & 33 & 41 & 38 & 25 & 28 \\
\hline Mean \pm SD & \multicolumn{2}{|c|}{$58.5 \pm 13.5$} & \multicolumn{2}{|c|}{$61.1 \pm 11.1$} & \multicolumn{2}{|c|}{$55.4 \pm 15.4$} \\
\hline \multicolumn{7}{|l|}{ Sex } \\
\hline Women & 89 & 45 & 59 & 55 & 30 & 34 \\
\hline Men & 108 & 55 & 49 & 45 & 59 & 66 \\
\hline \multicolumn{7}{|l|}{ Prisoner } \\
\hline Yes & 55 & 28 & 27 & 25 & 28 & 32 \\
\hline No & 142 & 72 & 81 & 75 & 61 & 68 \\
\hline \multicolumn{7}{|l|}{ ASA grade } \\
\hline 1 or 2 & 100 & 51 & 50 & 46 & 50 & 56 \\
\hline 3 & 97 & 49 & 58 & 54 & 39 & 44 \\
\hline Mean \pm SD & \multicolumn{2}{|c|}{$2.34 \pm 0.74$} & \multicolumn{2}{|c|}{$2.44 \pm 0.67$} & \multicolumn{2}{|c|}{$2.21 \pm 0.79$} \\
\hline \multicolumn{7}{|l|}{ BMI } \\
\hline$\leq 30 \mathrm{~kg} / \mathrm{m}^{2}$ & 95 & 48 & 43 & 40 & 52 & 58 \\
\hline$>30 \mathrm{~kg} / \mathrm{m}^{2}$ & 102 & 52 & 65 & 60 & 37 & 42 \\
\hline Mean \pm SD & \multicolumn{2}{|c|}{$31.1 \pm 6.3$} & \multicolumn{2}{|c|}{$32.2 \pm 6.8$} & \multicolumn{2}{|c|}{$29.9 \pm 5.5$} \\
\hline \multicolumn{7}{|c|}{ Maximum grade } \\
\hline 0 & 60 & 31 & 46 & 43 & 14 & 16 \\
\hline 1 & 54 & 27 & 21 & 19 & 33 & 37 \\
\hline 2 & 42 & 21 & 23 & 21 & 19 & 21 \\
\hline 3 & 20 & 10 & 12 & 11 & 8 & 9 \\
\hline 4 & 21 & 11 & 6 & 6 & 15 & 17 \\
\hline \multicolumn{7}{|l|}{ Total grade } \\
\hline 0 & 60 & 31 & 46 & 43 & 14 & 16 \\
\hline 1 & 43 & 22 & 15 & 14 & 28 & 32 \\
\hline 2 & 33 & 17 & 19 & 18 & 14 & 16 \\
\hline $3-6$ & 29 & 15 & 15 & 14 & 14 & 16 \\
\hline$\geq 7$ & 32 & 16 & 13 & 12 & 19 & 21 \\
\hline \multicolumn{7}{|l|}{ LOS } \\
\hline$\leq 3$ days & 65 & 33 & 26 & 24 & 39 & 44 \\
\hline$\geq 4$ days & 132 & 67 & 82 & 76 & 50 & 56 \\
\hline Mean \pm SD & \multicolumn{2}{|c|}{$4.80 \pm 2.78$} & \multicolumn{2}{|c|}{$5.30 \pm 3.22$} & \multicolumn{2}{|c|}{$4.19 \pm 2.00$} \\
\hline
\end{tabular}

Readmission or surgery within 90 days

\begin{tabular}{lcrcrlr} 
No & 183 & 93 & 102 & 94 & 81 & 91 \\
Yes & 14 & 7 & 6 & 6 & 8 & 9 \\
\hline $\begin{array}{l}\text { LOS = length } \\
\text { Anesthesiologists. }\end{array}$ & stay; & ASA = American & Society & of
\end{tabular}

and 89 women $(45 \%)$. Men had $45 \%(\mathrm{n}=49)$ of the TKAs and $66 \%(\mathrm{n}=59)$ of the THAs. The mean patient BMI was $31.1 \pm 6.3 \mathrm{~kg} / \mathrm{m}^{2}$ (range, $17-50 \mathrm{~kg} / \mathrm{m}^{2}$ ), and mean ASA score was $2.34 \pm 0.74$ (range, 1-3). The average LOS was $4.80 \pm 2.78$ days (range, 2-30 days) (Table 2). 
Table 3. Early adverse outcomes by maximum and total grades

\begin{tabular}{|c|c|c|c|c|c|c|}
\hline \multirow[t]{2}{*}{ Parameter } & \multicolumn{5}{|c|}{ Maximum grade } & \multirow[t]{2}{*}{$\mathrm{p}$ value } \\
\hline & 0 & 1 & 2 & 3 & 4 & \\
\hline LOS, days (mean $\pm \mathrm{SD}$ ) & $4.4 \pm 1.6$ & $4.1 \pm 1.5$ & $4.7 \pm 1.5$ & $7.5 \pm 6.2$ & $5.4 \pm 3.6$ & $<0.0001$ \\
\hline \multirow[t]{2}{*}{ Readmission or surgery within 90 days (number/\%) } & 0 & 0 & 0 & 10 & 4 & \multirow[t]{2}{*}{$<0.000$} \\
\hline & 0 & 0 & 0 & 50 & 19 & \\
\hline \multirow[t]{2}{*}{ Parameter } & \multicolumn{5}{|c|}{ Total grade } & \multirow[t]{2}{*}{$\mathrm{p}$ value } \\
\hline & 0 & 1 & 2 & $3-6$ & $\geq 7$ & \\
\hline LOS, days (mean $\pm \mathrm{SD})$ & $4.4 \pm 1.6$ & $3.8 \pm 1.4$ & $4.8 \pm 1.4$ & $5.3 \pm 1.9$ & $6.5 \pm 5.6$ & 0.0004 \\
\hline \multirow[t]{2}{*}{ Readmission or surgery within 90 days (number/\%) } & 0 & 0 & 0 & 3 & 11 & \multirow[t]{2}{*}{$<0.000$} \\
\hline & 0 & 0 & 0 & 10.3 & 34.4 & \\
\hline
\end{tabular}

LOS = length of stay.

\section{Results}

Maximum complication grade (range, 0-4) was associated with a longer LOS (for each point increase of maximum grade, LOS increased $0.105 \pm 0.024$ days, $\mathrm{p}<0.001)$ and more readmissions or reoperations (odds ratio [OR], 3.79; 95\% CI, 1.91-7.54; $\mathrm{p}<0.001$ ). Total grade (range, $0-22$ ) also was associated with increased LOS (for each point increase of total grade, LOS increased $0.032 \pm 0.006$ days, $\mathrm{p}<0.001)$ and increased readmissions or reoperations (OR, 1.34; 95\% CI, 1.18-1.53; p < 0.001) (Table 3). In the regression model, total grade accounted for $38 \%$ of the variation in LOS and readmissions or reoperations, and maximum complication grade accounted for $35 \%$ of the variation in LOS and readmissions or reoperations. Further logistical regression analysis to delineate which was the better predictor of increased LOS and readmissions or reoperations showed that total complication grade (C-statistics $=0.94 ; 95 \%$ CI, $0.90-0.98)$ was a better predictor of increased LOS and readmissions or reoperations than maximum complication grade $(\mathrm{C}$-statistics $=0.35 ; 95 \%$ CI, 0.88-0.96) (Table 4). (A C-statistical value of 1 indicates that a variable or model perfectly predicts the outcomes.) Patient sex, age, and BMI had no effect on either maximum complication grade (Table 5) or total complication grade (Table 6).

\section{Discussion}

Establishing a universal, standardized method for documenting and reporting medical complications is an integral part of assessing and improving healthcare [2, 9-11]. The Knee Society, in an effort to standardize complications reporting in orthopaedic surgery, developed a taskforce that identified and defined what they described as 22 "minimum necessary TKA complications" needed for accurate reporting of outcomes after knee replacement [12]. Subsequently, these complications were stratified by severity using a modification of the Clavien-Dindo surgical complication classification system, which has been widely adopted for use in general surgery and surgical subspecialties [3-9, 13-22, 24, 25]. To date, however, there have been no studies correlating the grade of orthopaedic complications and surgical outcomes. We sought to determine (1) whether an association exists between complication grade and length of stay and unplanned readmissions or reoperations and (2) what proportion of the variability in complications could be associated with the classification grade to establish this complication grading systems as a metric of quality and not merely a descriptive schema.

Our study has several limitations. The first, and perhaps most important, was the lack of a standardized definition of postoperative complications in orthopaedic surgery, apart from the list of postoperative complications devised by the workgroup of The Knee Society. During our study, The Knee Society's list of potential postoperative complications was readily accepted and could be easily expanded to hip arthroplasty. A more refined threshold for declaring unintended events as complications, possibly led by other specialty workgroups, would certainly clarify and enhance future complications reporting in the orthopaedic literature. A second limitation is our study is retrospective and consisted of a small number of patients from one center. Some patients, including those with incomplete data for review, may have sought care for postoperative complications at an outside medical facility, and therefore those complications may not have been documented in our records. Third, our 
Table 4. Multivariate analysis for predictors of early adverse outcomes

\begin{tabular}{|c|c|c|c|c|c|c|c|c|c|}
\hline \multirow[t]{2}{*}{ Parameter } & \multicolumn{4}{|l|}{ LOS } & \multicolumn{5}{|c|}{ Readmission or surgery within 90 days } \\
\hline & & SEM & Chi-square & $\mathrm{p}$ value & OR & $95 \% \mathrm{CI}$ & & Chi-square & $\mathrm{p}$ value \\
\hline Intercept & 1.023 & 0.2576 & 15.77 & $<0.0001$ & & & & & \\
\hline Maximum grade & 0.105 & 0.0243 & 18.62 & $<0.0001$ & 3.79 & $1.91-7.54$ & & 14.45 & 0.0001 \\
\hline Age & -0.009 & 0.0028 & 10.16 & 0.0014 & 1.00 & $0.95-1.05$ & & 0.01 & 0.9227 \\
\hline ASA grade & 0.2991 & 0.0556 & 28.99 & $<0.0001$ & 2.11 & $0.63-7.01$ & & 1.48 & 0.2238 \\
\hline BMI & -0.0046 & 0.0053 & 0.78 & 0.3784 & 0.94 & $0.85-1.05$ & & 1.24 & 0.265 \\
\hline Women & -0.0514 & 0.0876 & 0.34 & 0.5576 & 1.62 & $0.27-9.88$ & & 0.28 & 0.5998 \\
\hline Prisoner & 0.4072 & 0.0883 & 21.26 & $<0.0001$ & 0.86 & $0.10-7.30$ & & 0.02 & 0.8923 \\
\hline Knee & 0.3755 & 0.0752 & 24.96 & $<0.0001$ & 0.91 & $0.22-3.68$ & & 0.02 & 0.8901 \\
\hline $\mathrm{R}^{2}$ & 0.35 & & & & 0.16 & & & & \\
\hline C-statistics & & & & & 0.92 & $0.88-0.96$ & & & \\
\hline Intercept & 1.0192 & 0.253 & 16.23 & $<0.0001$ & & & & & \\
\hline Total grade & 0.0324 & 0.0055 & 35.32 & $<0.0001$ & 1.34 & $1.18-1.53$ & & 19.78 & $<0.0001$ \\
\hline Age & -0.0081 & 0.0027 & 9.01 & 0.0027 & 1.02 & $0.98-1.08$ & & 0.52 & 0.4717 \\
\hline ASA grade & 0.2817 & 0.0543 & 26.91 & $<0.0001$ & 1.5 & $0.45-5.04$ & & 0.43 & 0.5143 \\
\hline BMI & -0.0024 & 0.0052 & 0.21 & 0.6441 & 0.99 & $0.88-1.11$ & & 0.03 & 0.8539 \\
\hline Women & -0.0412 & 0.0847 & 0.24 & 0.6264 & 2.55 & $0.4-16.06$ & & 0.99 & 0.3195 \\
\hline Prisoner & 0.3969 & 0.0858 & 21.37 & $<0.0001$ & 1.99 & $0.25-15.97$ & & 0.42 & 0.5155 \\
\hline Knee & 0.3406 & 0.0703 & 23.47 & $<0.0001$ & 0.79 & $0.18-3.56$ & & 0.09 & 0.762 \\
\hline $\mathrm{R}^{2}$ & 0.38 & & & & 0.18 & & & & \\
\hline C-statistics & & & & & 0.94 & 0.90 & 0.98 & & \\
\hline
\end{tabular}

LOS = length of stay; SEM = standard error of the mean; OR = odds ratio; ASA = American Society of Anesthesiologists.

study population, which included a unique subpopulation of correctional facility inmates $(36 \%)$, may limit the applicability of our findings. However, for the intended purposes of this study, population diversity should not substantially affect our ability to classify postoperative complications. Fourth, although complication outcomes can be assessed in multiple ways, this study analyzed LOS and early readmissions or reoperations. LOS and unplanned readmissions or reoperations are tracked in pay for performance models and by institutions as a surrogate marker of quality. Our facility's discharge practices after primary arthroplasties are based on patients' meeting physical therapy goals and no longer requiring acute level care. This standard is for department of correction patients and private patients. Thus, although the exact number of LOS and readmissions or reoperations may not be the same at other facilities, we would expect that increased total and maximum complication grade would be associated with increased length of stay and unplanned readmissions or reoperations if the study were to be repeated at other institutions. Because our study was limited to TKAs and THAs, the modified classification system would have to be applied to a greater variety of musculoskeletal procedures before its efficacy across all aspects of orthopaedic surgery can be established. Finally, we introduced a mathematical concept of total complication and maximum complication grade to better evaluate the effect of the occurrence of multiple complications after one procedure.

To our knowledge, our study is the first to attempt to correlate complication grade, as determined by the modified Clavien-Dindo surgical system proposed by Iorio et al. [13], with orthopaedic surgical outcomes. LOS and readmission rates are widely used by quality care entities to assist in assessing outcomes, not only for institutions but also for surgeons, and therefore we chose to examine those outcomes. Given the multitude of complications that can be associated with a single surgical procedure, we introduced the concept of analyzing adverse outcomes in terms of maximum and total complication grades. We found the maximum and total complication grades of complications to be associated with increased LOS and readmissions or reoperations. Our findings are similar to those reported by Dindo and Clavien [9] when they used their classification 
Table 5. Patient demographics by maximum complication grade

\begin{tabular}{|c|c|c|c|c|c|c|c|}
\hline Parameter & $\begin{array}{l}\text { Total } \\
\mathrm{n}=197 \\
\text { Number }\end{array}$ & $\begin{array}{l}\text { Grade } 0 \\
\mathrm{n}=60 \\
31 \% \\
\%\end{array}$ & $\begin{array}{l}1 \\
\mathrm{n}=54 \\
27 \% \\
\%\end{array}$ & $\begin{array}{l}2 \\
\mathrm{n}=42 \\
21 \% \\
\%\end{array}$ & $\begin{array}{l}3 \\
\mathrm{n}=20 \\
10 \% \\
\%\end{array}$ & $\begin{array}{l}4 \\
\mathrm{n}=21 \\
11 \% \\
\%\end{array}$ & $\mathrm{p}$ value \\
\hline \multicolumn{8}{|l|}{ Age (years) } \\
\hline$<50$ & 42 & 31 & 26 & 21 & 10 & 12 & \multirow[t]{4}{*}{0.8261} \\
\hline $50-59$ & 60 & 35 & 28 & 15 & 13 & 8 & \\
\hline $60-69$ & 53 & 34 & 28 & 23 & 6 & 9 & \\
\hline$\geq 70$ & 42 & 19 & 26 & 29 & 12 & 14 & \\
\hline \multicolumn{8}{|l|}{ Sex } \\
\hline Women & 89 & 33 & 23 & 24 & 11 & 10 & \multirow[t]{2}{*}{0.6782} \\
\hline Men & 108 & 29 & 32 & 19 & 9 & 11 & \\
\hline \multicolumn{8}{|l|}{ Prisoner } \\
\hline Yes & 55 & 36 & 22 & 16 & 9 & 16 & \multirow[t]{2}{*}{0.2835} \\
\hline No & 142 & 28 & 30 & 23 & 11 & 9 & \\
\hline \multicolumn{8}{|l|}{ Joint } \\
\hline Knee & 108 & 43 & 19 & 21 & 11 & 6 & \multirow[t]{2}{*}{$0.0001^{*}$} \\
\hline Hip & 89 & 16 & 37 & 21 & 9 & 17 & \\
\hline \multicolumn{8}{|l|}{ ASA grade } \\
\hline 1 & 31 & 42 & 32 & 13 & 0 & 13 & \multirow[t]{3}{*}{0.1418} \\
\hline 2 & 69 & 38 & 22 & 20 & 10 & 10 & \\
\hline 3 & 97 & 22 & 30 & 25 & 13 & 10 & \\
\hline \multicolumn{8}{|l|}{ BMI } \\
\hline Normal & 30 & 20 & 27 & 27 & 13 & 13 & \multirow[t]{4}{*}{0.6718} \\
\hline Overweight & 65 & 23 & 28 & 25 & 9 & 15 & \\
\hline Obese & 57 & 39 & 28 & 18 & 11 & 5 & \\
\hline Morbidly obese & 45 & 38 & 27 & 18 & 9 & 9 & \\
\hline
\end{tabular}

* Significant; ASA = American Society of Anesthesiologists.

system to assess elective general surgery procedures. In their study, only the highest grade of complication was documented in patients with multiple complications. Nonetheless, they also determined that surgery complexity and LOS strongly correlated with increasing grade [9]. In our study, total complication grade was a better predictor of LOS than maximum complication grade, and this finding suggests that multiple complications of a lesser grade can be just as important as one higher-grade complication in terms of effect on outcomes.

Although there are other modalities one can use to anticipate postoperative complications such as ASA score and the Charlson comorbidity index, the current classification system we used provides a standardized reproducible way of grading complications once they have occurred, which is essential for complication reporting in the orthopaedic literature. The Knee Society grading systems provides a standardized, reproducible method of grading and reporting complications. As our study shows, beyond being merely descriptive, it is a predictor of quality regarding LOS and unplanned readmissions or reoperations.

We found that the modified Clavien-Dindo surgical classification system [13] is applicable to TKA and THA in terms of documentation of complication severity and as an indicator of early adverse outcomes with respect to LOS and readmissions or reoperations. Future studies using preestablished complications for various orthopaedic procedures in a larger number of patients are needed to show the general applicability of the modified Clavien-Dindo surgical classification system for orthopaedic surgical procedures. 
Table 6. Patient demographics by total complication grade

\begin{tabular}{|c|c|c|c|c|c|c|c|}
\hline Parameter & $\begin{array}{l}\text { Total } \\
\mathrm{n}=197 \\
100 \% \\
\text { Number }\end{array}$ & $\begin{array}{l}\text { Grade } 0 \\
\mathrm{n}=60 \\
31 \% \\
\%\end{array}$ & $\begin{array}{l}1 \\
\mathrm{n}=43 \\
22 \% \\
\%\end{array}$ & $\begin{array}{l}2 \\
\mathrm{n}=33 \\
17 \% \\
\%\end{array}$ & $\begin{array}{l}3-6 \\
\mathrm{n}=29 \\
15 \% \\
\%\end{array}$ & $\begin{array}{l}\geq 7 \\
\mathrm{n}=32 \\
16 \% \\
\%\end{array}$ & $\mathrm{p}$ value \\
\hline \multicolumn{8}{|l|}{ Age (years) } \\
\hline$<50$ & 42 & 31 & 21 & 12 & 17 & 19 & 0.149 \\
\hline $50-59$ & 60 & 35 & 28 & 7 & 12 & 18 & \\
\hline $60-69$ & 53 & 34 & 19 & 26 & 11 & 9 & \\
\hline$\geq 70$ & 42 & 19 & 17 & 24 & 21 & 19 & \\
\hline \multicolumn{8}{|l|}{ Sex } \\
\hline Women & 89 & 33 & 16 & 21 & 15 & 16 & 0.279 \\
\hline Men & 108 & 29 & 27 & 13 & 15 & 17 & \\
\hline \multicolumn{8}{|l|}{ Prisoner } \\
\hline Yes & 55 & 36 & 22 & 7 & 13 & 22 & 0.1566 \\
\hline No & 142 & 28 & 22 & 20 & 16 & 14 & \\
\hline \multicolumn{8}{|l|}{ Joint } \\
\hline Knee & 108 & 43 & 14 & 18 & 14 & 12 & $0.0003 *$ \\
\hline Hip & 89 & 16 & 32 & 16 & 16 & 21 & \\
\hline \multicolumn{8}{|l|}{ ASA grade } \\
\hline 1 & 31 & 42 & 32 & 7 & 6 & 13 & 0.0943 \\
\hline 2 & 69 & 38 & 20 & 16 & 13 & 13 & \\
\hline 3 & 97 & 22 & 20 & 21 & 19 & 19 & \\
\hline \multicolumn{8}{|l|}{ BMI } \\
\hline Normal & 30 & 20 & 20 & 17 & 20 & 23 & 0.6606 \\
\hline Overweight & 65 & 23 & 23 & 22 & 14 & 18 & \\
\hline Obese & 57 & 39 & 25 & 14 & 12 & 10 & \\
\hline Morbidly obese & 45 & 38 & 18 & 13 & 16 & 16 & \\
\hline
\end{tabular}

* Significant; ASA = American Society of Anesthesiologists.

\section{References}

1. Annas GJ. The patient's right to safety: improving the quality of care through litigation against hospitals. $N$ Engl $J$ Med. 2006;354:2063-2066.

2. Belmont PJ Jr, Goodman GP, Waterman BR, Bader JO, Schoenfeld AJ. Thirty-day postoperative complications and mortality following total knee arthroplasty: incidence and risk factors among a national sample of 15,321 patients. J Bone Joint Surg Am. 2014;96:20-26.

3. Chun YS, Vauthey JN, Ribero D, Donadon M, Mullen JT, Eng C, Madoff DC, Chang DZ, Ho L, Kopetz S, Wei SH, Curley SA, Abdalla EK. Systemic chemotherapy and two-stage hepatectomy for extensive bilateral colorectal liver metastases: perioperative safety and survival. J Gastrointest Surg. 2007;11:1498-1504; discussion 1504-1505.

4. Clavien PA, Barkun J, de Oliveira ML, Vauthey JN, Dindo D, Schulick RD, de Santibañes E, Pekolj J, Slankamenac K, Bassi C, Graf R, Vonlanthen R, Padbury R, Cameron JL, Makuuchi M. The Clavien-Dindo classification of surgical complications: fiveyear experience. Ann Surg. 2009;250:187-196.

5. Clavien PA, Sanabria JR, Strasberg SM. Proposed classifications of surgery with examples of utility in cholecystectomy. Surgery. 1992;111:518-526.

6. DeOliveira ML, Winter JM, Schafer M, Cunningham SC, Cameron JL, Yeo CJ, Clavien PA. Assessment of complications after pancreatic surgery: a novel grading system applied to 633 patients undergoing pancreaticoduodenectomy. Ann Surg. 2006;244:931-937; discussion 937-939.

7. de Santibanes E, Ardiles V, Gadano A, Palavecino M, Pekolj J, Ciardullo M. Liver transplantation: the last measure in the treatment of bile duct injuries. World J Surg. 2008;32:1714-1721.

8. Dindo D, Clavien PA. What is a surgical complication? World J Surg. 2008; 32:939-941.

9. Dindo D, Demartines N, Clavien PA. Classification of surgical complications: a new proposal with evaluation in a cohort of 6336 patients and results of a survey. Ann Surg. 2004;240:205213.

10. Goldhahn S, Sawaguchi T, Audigé L, Mundi R, Hanson B, Bhandari M, Goldhahn J. Complication reporting in orthopaedic trials: a systematic review of randomized controlled trials. J Bone Joint Surg Am. 2009;91:1847-1853.

11. Hall JC. How to dissect surgical journals: VII. The concept of outcome. ANZ J Surg. 2011:81: 91-94.

12. Healy WL, Della Valle CJ, Iorio R, Berend KR, Cushner FD, Dalury DF, Lonner JH. Complications of total knee arthroplasty: standardized list and definitions of The Knee Society. Clin Orthop Relat Res. 2013;471:215-220.

13. Landriel Ibañez FA, Hem S, Ajler P, Vecchi E, Ciraolo C, Baccanelli M, Tramontano R, Knezevich F, Carrizo A. A new classification of complications in neurosurgery. World Neurosurg. 2011;75:709-715. 
14. Iorio R, Della Valle CJ, Healy WL, Berend KR, Cushner FD, Dalury DF, Lonner JH. Stratification of standardized TKA complications and adverse events: a brief communication. Clin Orthop Relat Res. 2014;472:194-205.

15. Ksouri H, Balanant PY, Tadié JM, Heraud G, Abboud I, Lerolle N, Novara A, Fagon JY, Faisy C. Impact of morbidity and mortality conferences on analysis of mortality and critical events in intensive care practice. Am J Crit Care. 2010;19:135-145; quiz 146.

16. McKay A, Sutherland FR, Bathe OF, Dixon E. Morbidity and mortality following multivisceral resections in complex hepatic and pancreatic surgery. J Gastrointest Surg. 2008;12:86-90.

17. Patel S, Cassuto J, Orloff M, Tsoulfas G, Zand M, Kashyap R, Jain A, Bozorgzadeh A, Abt P. Minimizing morbidity of organ donation: analysis of factors for perioperative complications after living-donor nephrectomy in the United States. Transplantation. 2008;85:561-565.

18. Permpongkosol S, Link RE, Su LM, Romero FR, Bagga HS, Pavlovich CP, Jarrett TW, Kavoussi LR. Complications of 2,775 urological laparoscopic procedures: 1993 to 2005. J Urol. 2007; 177:580-585.

19. Reddy SK, Morse MA, Hurwitz HI, Bendell JC, Gan TJ, Hill SE, Clary BM. Addition of bevacizumab to irinotecan-and oxaliplatin-based preoperative chemotherapy regimens does not increase morbidity after resection of colorectal liver metastases. J Am Coll Surg. 2008;206:96-106.
20. Reddy SK, Pawlik TM, Zorzi D, Gleisner AL, Ribero D, Assumpcao L, Barbas AS, Abdalla EK, Choti MA, Vauthey JN, Ludwig KA, Mantyh CR, Morse MA, Clary BM. Simultaneous resections of colorectal cancer and synchronous liver metastases: a multi-institutional analysis. Ann Surg Oncol. 2007;14:3481-3491.

21. Ribero D, Abdalla EK, Madoff DC, Donadon M, Loyer EM, Vauthey JN. Portal vein embolization before major hepatectomy and its effects on regeneration, resectability and outcome. $\mathrm{Br} \mathrm{J}$ Surg. 2007;94:1386-1394.

22. Seda-Neto J, Godoy AL, Carone E, Pugliese V, Fonseca EA, Porta G, Pugliese R, Miura IK, Baggio V, Kondo M, Chapchap P. Left lateral segmentectomy for pediatric live-donor liver transplantation: special attention to segment IV complications. Transplantation. 2008;86:697-701.

23. Sink EL, Beaulé PE, Sucato D, Kim YJ, Millis MB, Dayton M, Trousdale RT, Sierra RJ, Zaltz I, Schoenecker P, Monreal A, Clohisy J. Multicenter study of complications following surgical dislocation of the hip. J Bone Joint Surg Am. 2011;93:1132-1136.

24. Sundaram CP, Martin GL, Guise A, Bernie J, Bargman V, Milgrom M, Shalhav A, Govani M, Goggins W. Complications after a 5-year experience with laparoscopic donor nephrectomy: the Indiana University experience. Surg Endosc. 2007;21:724-728.

25. Tamura S, Sugawara Y, Kaneko J, Yamashiki N, Kishi Y, Matsui Y, Kokudo N, Makuuchi M. Systematic grading of surgical complications in live liver donors according to Clavien's system. Transpl Int. 2006;19:982-987. 